\title{
Interfacial role of Cesium in Prussian Blue Films
}

R. Catalán ${ }^{1}$, J. Agrisuelas ${ }^{1, *}$, A. Cuenca ${ }^{1}$, J. J. García-Jareño ${ }^{1}$, A. F. Roig ${ }^{2}$, F. Vicente ${ }^{1, \S}$

${ }^{1}$ Department of Physical Chemistry. University of Valencia. C/. Dr. Moliner,50. 46100Burjassot (Spain).

${ }^{2}$ Department of Analytical and Physical Chemistry. UJI, Avda. Sos Bainat, s/n. Castelló (Spain).

*e-mail: jeronimo.agrisuelas@uv.es

$\S^{\S}$ ECS member 


\begin{abstract}
The simultaneous measurement of current, mass, motional resistance and absorbance magnitudes allows the electrochemical cation insertion process to be explained during successive voltammograms around the Prussian Blue $\rightleftarrows$ Everitt's Salt system in $\mathrm{CsCl}$ aqueous acid solutions. Two different ways for the entrance of cesium to the porous structure of Prussian Blue have been observed. Firstly, $\mathrm{Cs}^{+}$is spontaneously absorbed as $\mathrm{CsCl}$ into the interstitial cluster of water of the channels formed by the $\mathrm{Fe}(\mathrm{II})_{\text {low spin }}-\mathrm{CN}-\mathrm{Fe}(\mathrm{III})_{\text {high spin }}$ structural units of the crystal. This chemical absorption involves a spontaneous substitution of inner water molecules of the interstitial water cluster. Finally, $\mathrm{Cs}^{+}$can act as a counter-ion during electrochemical stabilization process of Prussian Blue by means of successive voltammograms.
\end{abstract}

Keywords: Electrochemistry, QCM-R, Motional Resistance, Prussian Blue, Removal of Cesium. 


\section{Introduction}

Electrodeposited films of Prussian Blue (PB), one of the most studied smart materials, have been investigated during the last thirty years for their important technological applications (i.e. electrochromic devices) ${ }^{1-8}$. The Prussian Blue films freshly deposited following the electrochemical procedure described by Itaya et al. are in the "insoluble" form" ${ }^{7}$ This film contents alkaline cations at trace level only ${ }^{9,10}$. However, a compositional change takes place after few successive voltammetric cycles around the colored PB and colorless Everitt's salt forms ( $\mathrm{PB} \rightleftarrows \mathrm{ES}$ system) in $\mathrm{KCl}$ aqueous solutions with a $\mathrm{pH}$ around three. This process of electrochemical stabilization transforms “insoluble" PB into "soluble" PB.

Structural studies suggest that the crystalline cell units of "soluble" and "insoluble" forms are very similar and the main chemical difference is the presence of $\mathrm{K}$ into the crystalline structure of the "soluble"11,12. The postulated formula of the "soluble" form stabilized in presence of $\mathrm{K}^{+}$is ${ }^{13,14}$ :

$$
\mathrm{Fe}_{4}^{\mathrm{III}}\left[\mathrm{Fe}^{\mathrm{II}}(\mathrm{CN})_{6}\right]_{3} \cdot\left[\left(\mathrm{K}^{+}\right)_{2} \cdot\left(\mathrm{OH}^{-}\right)_{2} \cdot\left(\mathrm{mH}_{2} \mathrm{O}\right)\right]_{3}
$$

Crystalline PB structure has a face-centered cubic lattice that shows two different types of water molecules: coordinated water into vacancies and uncoordinated water in interstitial positions ${ }^{15,16}$. Consequently, the content of inner water affects directly to all physical properties of the material. Then, it is possible to describe the structure of Prussian Blue as a cluster of water molecules inside a rigid skeleton formed by $\mathrm{Fe}(\mathrm{II})_{\text {low }}$ spin- $\mathrm{CN}-\mathrm{Fe}(\mathrm{III})$ high spin units where water is the carrier of ionic species involved in the electrochemical processes of these electrochromic films ${ }^{17,18}$.

From a spectroscopic perspective, the absorption band around $670 \mathrm{~nm}$ is particularly interesting since it is associated with $\mathrm{Fe}(\mathrm{II})_{\text {low spin }}-\mathrm{CN}-\mathrm{Fe}(\mathrm{III})_{\text {high spin }}$ structural units forming the rigid skeleton of the PB. This band is caused by the electron charge 
transfer from the $\mathrm{Fe}(\mathrm{II})$ atoms surrounded by $-\mathrm{CN}$ units to the $\mathrm{Fe}(\mathrm{III})$ atoms surrounded by $-\mathrm{NC}$ units ${ }^{13,18}$. Furthermore, this band and its electrochromic efficiency remain unaltered during the transformation of insoluble PB to soluble PB in the stabilization $\operatorname{process}^{19}$.

Quartz crystal microbalance (QCM) is a mass detection device based on the piezoelectric resonant frequencies of quartz crystal placed in an oscillator circuit ${ }^{20}$. The first quantitative description was given by Sauerbrey equation ${ }^{21}$. The decrease in frequency, $\Delta f_{r}$, shows a linear relationship with the electrode mass shift, $\Delta m$, when adsorbed films on resonator sensor are uniform, elastic (acoustically thin), and ultrathin:

$$
\Delta f_{r}=-\frac{2 f_{q}^{2}}{A \sqrt{\rho_{q} \mu_{q}}} \Delta m
$$

where $f_{q}$ is the fundamental resonant frequency of quartz in air, $A$ is the piezoelectrically active area, $\rho_{q}$ is the density of quartz, and $\mu_{q}$ is the shear modulus of quartz.

In many situations, the adsorbed film shows viscoelastic properties because of physical intrinsic properties of film or when is thick enough. This film will not fully couple to the oscillation of the crystal and will dampen the oscillations of resonator. In spite of the Sauerbrey relation becomes invalid in this situation, Etchenique and coworkers showed the possibility of making gravimetric use of the QCM beyond the Sauerbrey limit using the Martin's viscoelastic model ${ }^{22}$.

The changes of mechanical/structural and viscoelastic properties of adsorbed molecules can be evaluated by measuring the elements of the QCM equivalent circuit by fitting experimental admittance-frequency $\left(Y-f_{r}\right)$ curves $^{23,24}$. The Butterworth-Van Dyke (BVD) equivalent circuit consists of two branches that represent a static capacitance $\left(C_{s}\right)$ in parallel with a motional (or resonant) branch with the motional inductance, $L_{m}$, 
the motional capacitance, $C_{m}$, and the motional resistance $R_{m}$ in series. The complete electrical admittance of the loaded quartz resonator is:

$$
Y(\omega)=j \omega C_{p}+\frac{1}{R_{m}+j \omega L_{m}+\frac{1}{j \omega C_{m}}}=j \omega C_{p}+\frac{1}{Z_{m}(\omega)}
$$

where $\omega=2 \pi f_{r}$ is the angular frequency, $j=\sqrt{-1}$ and $Z_{m}$ is the motional impedance.

Each element of the electroacoustic model has a relation between the mechanical properties of the three-layer compound resonator: the piezoelectric properties of the quartz crystal $(q)$, the viscoelastic behavior of the film $(f)$ and the shear parameter of the liquid medium $(s)^{25,26}$. If the characteristics of the quartz and of the liquid are considered as constant, $Z_{m}(\omega)$ can be described according to the viscoelastic model of Granstaff and Martin as ${ }^{27}$ :

$$
Z_{m}(\omega)=\frac{h_{q}^{2}}{4 e_{q}^{2} A} Z_{f}+\frac{Z_{s}+Z_{f} \tanh \left(\theta_{f} h_{f}\right)}{Z_{f}+Z_{s} \tanh \left(\theta_{f} h_{f}\right)}
$$

where $h_{f}$ and $h_{q}$ are the thicknesses of the film and quartz crystal respectively, $e_{q}$ is the quartz piezoelectric constant, $Z_{s}$ is the acoustic impedance of solution, $Z_{f}=\sqrt{\rho_{f} G_{f}}$ is the acoustic impedance of film, $\theta_{f}=\sqrt{\rho_{f} / G_{f}}$ the complex propagation constant of the film where $\rho_{f}$ is the film density. $G_{f}=G_{f}^{\prime}+j G_{f}^{\prime \prime}$ is the complex shear modulus of film where $G_{f}^{\prime}$ is the stiffness of rigidity coefficient and $G_{f}^{\prime \prime}$ is considered as the loss term. From the real part of Eq. [4], the motional resistance of the BVD equivalent circuit can be expressed $\operatorname{as}^{28}$ :

$$
R_{m}=\frac{\pi^{2} \eta_{q} h_{q}}{8 K^{2} c_{66} \xi_{22} A}+\frac{h_{q}^{2}}{4 e_{q}^{2} A}\left(\frac{\omega^{2} \rho_{f}^{3 / 2} h_{f}^{2} G_{f}^{\prime}}{\left(G_{f}^{\prime \prime}\right)^{2}-\left(G_{f}^{\prime}\right)^{2}}\right)+\frac{h_{q}^{2}}{4 e_{q}^{2} A} \sqrt{\frac{\omega \rho_{s} \eta_{s}}{2}}
$$

where $\eta$ is the viscosity, $K$ is the electromechanical coupling factor for no loss quartz, $c_{66}$ is the piezoelectrically stiffened elastic constant for no loss quartz, $e_{q}$ is the piezoelectric stress constant for quartz, $\rho_{s}$ is the solution density and $\xi_{22}$ is the quartz permittivity. The 
versatility of this magnitude provides information of magnetic properties ${ }^{28}$, molecular interactions $^{29,30}$, porosity of film ${ }^{22}$, metal conversions ${ }^{31}$, and electrocatalysis ${ }^{32}$.

The motional resistance is related to the energy dissipation during oscillation due to internal friction, mechanical losses in the mounting system and acoustical losses to the surrounding environment ${ }^{33}$. If the characteristics of the quartz and of the liquid are considered as constant, then, $R_{m}$ becomes a function of $\rho_{f}, h_{f}, G_{f}^{\prime}$ and $G_{f}^{\prime \prime}$ to characterize conducting films. The viscoelasticity depends both on the electrolyte composition and film charge or redox state ${ }^{24,34}$. The solvent incorporated into the polymer network can lead to swelling and can act as plasticizer of the polymer ${ }^{35}$. However, for the sake of unifying the fitted parameters, either the film thickness and/or the film density has to be maintained constant ${ }^{24,36}$. This is a good approximation but conducting films may change, during the electrochemical transitions, the thickness to store inserted ions or water molecules by molecular arrangements ${ }^{37-40}$ and the global density considering the polymeric chains, counter-ions and water molecules condensed in a finite space (dense gel $)^{41,42}$.

Taking advantage of current and mass provided by the electrochemical QCM, we could obtain the mass/charge ratio. This function gives information about the nature of species or about the mechanism of an electrochemical reaction involving changes of mass on the electrode surface considering the Faraday's law ${ }^{43}$ :

$$
F\left(\frac{d m}{d q}\right)=F\left(\frac{d m / d t}{j}\right)=\sum v_{i} \frac{M_{i}}{n_{i}}
$$

where $M_{i}$ is the molar mass of charged $i$ specie, which is involved in the charge balance of $n_{i}$ electrons and $v_{i}$ represents a percentage of the electrical charge balanced by the participation of this ion. However, we must take care with the results of Eq. [6] because neutral species participate during the ionic exchanges in some reactive systems, which involve mass changes, but they do not cause a flux of electrical charge. 
After a nuclear power plant disaster like recently in the Fukushima prefecture (Japan), long living radioisotopes of cesium are released to the environment. The cesium is water-soluble; therefore, cesium removal from radioactive wastes becomes one of the most important decontamination aims. Interestingly, PB-like hexacyanometallates have the capacity to absorb cesium from this kind of wastes ${ }^{4-47}$. The present work is focused on the analysis of the stabilization of "insoluble" PB films galvanostatically deposited on the gold electrode of a quartz resonator or on a transparent indium-tin oxide (ITO) electrode when the counter cation that enters into the framework of PB is cesium. For that, the processes, which involve the PB electrochemistry around the $\mathrm{PB} \rightleftarrows \mathrm{ES}$ system was investigated in $0.5 \mathrm{M} \mathrm{CsCl}$ aqueous solution at low $\mathrm{pH}$. This study was carried out by means of simultaneous measurements of the resonance frequency of quartz and the motional resistance simultaneously measured with a QCM with motional resistance monitoring (QCM-R).

\section{Experimental}

Insoluble PB films were electrochemically deposited by immersion in $0.02 \mathrm{M}$ $\mathrm{K}_{3} \mathrm{Fe}(\mathrm{CN})_{6}$ (analytical reagent, Scharlau), $0.02 \mathrm{M} \mathrm{FeCl}_{3} \cdot 6 \mathrm{H}_{2} \mathrm{O}$ (analytical reagent, Scharlau), and $\mathrm{HCl}$ (analytical reagent, Scharlau) solution. A controlled cathodic current of $40 \mu \mathrm{A} . \mathrm{cm}^{-2}$ was applied for $150 \mathrm{~s}$ to obtain "insoluble" PB films ${ }^{7}$.

Once the "insoluble" form were deposited on the working electrode, the film was conditioned during 60 seconds applying $0.6 \mathrm{~V}$ in $0.5 \mathrm{M} \mathrm{CsCl}$ (Scharlau RA) at $\mathrm{pH}=2.7$ (adding some concentrated $\mathrm{HCl}$ drops). Then, "soluble" $\mathrm{PB}$ was generated by cycling the electrochemical system between $0.6 \mathrm{~V}(\mathrm{~PB})$ and $-0.2 \mathrm{~V}(\mathrm{ES})$ in the same solution at 20 $\mathrm{mV} \mathrm{s}^{-1}$. A thermostatized three-electrode cell was used for simultaneous spectroscopic and electrogravimetric experiences. A high surface mesh of $\mathrm{Pt} / \mathrm{Ir}$ was used as counter electrode. All potentials were referred to the $\mathrm{Ag}|\mathrm{AgCl}| \mathrm{KCl}_{\text {(sat) }}$ reference electrode. An 
Autolab potentiostat-galvanostat (POSTAT304) was used in the voltammetric measurements, whereas a QCM-R (RQCM, Maxtek Inc.) was used to record the motional resistance and changes of frequencies of resonant quartz during the stabilization process. Calibration of gold/quartz-crystal electrodes was carry out by means of a galvanostatic deposition $\left(2 \mathrm{~mA} \mathrm{~cm}^{-2}\right)$ of $\mathrm{Cu}$ from a $0.5 \mathrm{M} \mathrm{CuSO}_{4}\left(\mathrm{H}_{2} \mathrm{O}\right)_{5}$ solution in a $0.1 \mathrm{M} \mathrm{H}_{2} \mathrm{SO}_{4}$ at $\mathrm{pH}=1.92$ (both chemicals were reagent grade, Scharlau).

The working electrodes were high reflectance gold/quartz-crystal electrodes of 20 $\mathrm{mm}^{2}$ (AT-cut quartz crystal, $9 \mathrm{MHz}$ Matel-Fordahl). That allows the in situ measures of Visible-NIR transmittance of the PB deposited to be performed by an Ocean Optics TM DH-2000-BAL Spectrometer. The color response reflected on the diode-array of spectrometer from gold/quartz-crystal electrodes was received as number of counts at each wavelength, $n_{\text {counts }}^{\lambda}$ which, is directly converted into light intensity at a given wavelength, $I^{\lambda}$. In this work, an apparent time derivative of absorbance at a specific wavelength $\left(A^{\lambda}\right)$ is calculated for comparing with mass and electrical charge changes by means of the Lambert-Beer's law:

$$
\begin{gathered}
A^{\lambda}=-\log \left(\frac{I^{\lambda}}{I_{0}^{\lambda}}\right)=-\log \left(I^{\lambda}\right)+\log \left(I_{0}^{\lambda}\right) \\
\frac{d A^{\lambda}}{d t}=\frac{d\left(-\log \left(I^{\lambda}\right)+\log \left(I_{0}^{\lambda}\right)\right)}{d t}=-\frac{d\left(\ln \left(I^{\lambda}\right)\right)}{\ln (10) \cdot d t}=-\frac{1}{2.303 I^{\lambda}} \frac{d I^{\lambda}}{d t}
\end{gathered}
$$

Since, the intensity of transmitted light, $I^{\lambda}$, is proportional to the number of counts, $n_{\text {counts }}^{\lambda}$, received by the diode at this wavelength, it can be written:

$$
\frac{d A^{\lambda}}{d t}=-\frac{1}{2.303 I^{\lambda}} \frac{d I^{\lambda}}{d t}=-\frac{1}{2.303 n_{\text {counts }}^{\lambda}} \frac{d n_{\text {counts }}^{\lambda}}{d t}
$$

Later, raw data of absorbance were smoothed leaving out noise using the software Mathcad 14 (Mathsoft). 
An Agilent 7500cx ICPMS (equipped with collision cell) was used for concentration measurements. Quantitative determination of Cs in PB films was carried out through Inductively Coupled Plasma Mass Spectrometry (ICP-MS) after film dissolution in concentrated ammonia. EDTA was added to prevent metal hydroxides precipitation. In this occasion, indium-tin oxide (ITO) electrodes of $1 \mathrm{~cm}^{2}$ were used (30 $\Omega /$ sq.). ITO electrodes with deposited "soluble" PB films were immersed in $2 \mathrm{~mL}$ of a freshly prepared concentrated solution of $\mathrm{NH}_{3}: 0.01 \mathrm{M}$ EDTA (1:4) and sonicated during 1 minute. The solution was quantitatively collected, diluted to $20 \mathrm{~mL}$ with $0.001 \mathrm{M}$ EDTA and directly aspirated to the ICPMS. $\mathrm{NH}_{3}$ (Trace Select Ultra) was from Fluka and EDTA disodium salt (Molecular Biology) from Scharlau.

\section{Results and Discussion}

After PB electrodeposition, the "insoluble" film was immersed in $0.5 \mathrm{M} \mathrm{CsCl}$ aqueous solution at $\mathrm{pH}=2.7$ for the electrochemical transformation to the "soluble" film by means of cyclic voltammetry. Fig. 1 shows the mass (Fig. 1a) and motional resistance

(Fig. 1b) responses during the first and tenth stabilization cycle. Motional resistance is expressed as increment taking as the reference value the initial $R_{m}$ value of collected data series. Thus, $\Delta R_{m}$ in Fig. $1 \mathrm{~b}$ shows the changes of viscoelastic properties of PB film caused by electrochemical reactions involved during the potential sweeps.

The main difference between both cycles is the irreversibility observed in the first cycle. The most significant $\mathrm{Cs}^{+}$insertion takes place during the first reduction process with a mass increment of $7 \mu \mathrm{g} \mathrm{cm}^{-2}$ (Fig. 1a). After first reduction of "insoluble" PB, "soluble" form of $\mathrm{PB}$ is formed in $\mathrm{CsCl}$ solutions by the insertion of $\mathrm{Cs}^{+}$together with a significant amount of water molecules excluded ${ }^{48,49}$. Both processes are responsible for an evident increase of motional resistance of about $48 \Omega$ (Fig. 1b). Therefore, the first electrochemical insertion of $\mathrm{Cs}^{+}$involves significant structural and viscoelastic changes 
in the PB film. Later, the first oxidation process does not achieve the original values in both magnitudes. The successive cycles show a practically reversible variation of mass and $\Delta R_{m}$ similar to the cycle 10 in Fig. 1.

These changes are consequence of the electrochemical behavior of PB film during the stabilization process (Fig. 2). In spite of the shape of voltammograms does not change appreciably, some differences can be mentioned. In general, two voltammetric peaks are observed around $0.4-0.5 \mathrm{~V}$ and $0.1-0.2 \mathrm{~V}$ in all voltammograms. The main difference is observed in the cathodic sweep of first cycle where a shoulder around $0.1 \mathrm{~V}$ appears. This peak coincides with the high increment of mass and $\Delta R_{m}$ mentioned above.

Compared with voltammetry of $\mathrm{PB}$ films in $\mathrm{KCl}$ aqueous solutions ${ }^{50,51}$, the transformation of the freshly generated "insoluble" PB to the "soluble" and stabilized PB in $\mathrm{CsCl}$ aqueous solution shows wider and smaller voltammetric peaks. Moreover, the entrance of cation $\mathrm{Cs}^{+}$into PB films causes a loss of their electrical conductivity and lifetimes with respect to the entrance of other cations like potassium or ammonium ${ }^{50,51}$. In this case, cesium cations can be easily inserted in the PB film because they easily lose their hydration sphere in solution ${ }^{52}$.

In the Fig. 2, the function $F(d m / d q)$ (Eq. [6]) includes the pondered contribution of all species interchanged between PB film and the solution in both reduction and oxidation directions for cycle 1 and 10 . Around $0.15 \mathrm{~V}$ during the reduction process of cycle 1 (Fig. $2 \mathrm{a}), F(d m / d q)$ shows values close to $-80 \mathrm{~g} \mathrm{~mol}^{-1}$. Theoretically, $F(d m / d q)$ function of $\mathrm{Cs}^{+}$insertion involving one electron transfer would be the same value than molar mass of Cs (about $133 \mathrm{~g} \mathrm{~mol}^{-1}$ ). A lower value indicates the participation of different species, as it was suggested by ac-electrogravimetry ${ }^{52}$. This hypothesis agrees also with previous experimental results which prove that water molecules $\left(18 \mathrm{~g} \mathrm{~mol}^{-1}\right)$ and protons $\left(1 \mathrm{~g} \mathrm{~mol}^{-1}\right)$ but not anions within the PB film play a very important role 
during electrochemical processes ${ }^{53}$. The complex electrochemical system of PB films involving several specie transfers does not allow the $v_{i}$ of each participating specie to be easily find out because several combinations give the same result. However, $-80 \mathrm{~g} \mathrm{~mol}^{-1}$ proves clear the main electrochemical insertion of $\mathrm{Cs}^{+}$during the first reduction of "insoluble" PB film. Once we have a "soluble" $\mathrm{PB}, \mathrm{Cs}^{+}$counterion is interchanged during the first oxidation with the medium around $0.6 \mathrm{~V}$ considering the values of the $F(d m / d q)$ (again around $-80 \mathrm{~g} \mathrm{~mol}^{-1}$ ).

In the following voltammetric cycles, $F(d m / d q)$ function shows similar behavior independently of oxidation and reduction process (Fig. 2b). Principally, we observe higher values of $F(d m / d q)$ function than $+50 \mathrm{~g} \mathrm{~mol}^{-1}$ around $0.6 \mathrm{~V}$. Therefore, we assume the participation of $\mathrm{Cs}^{+}$as the main counterion to balance the charge defects. As potential is more cathodic, $F(d m / d q)$ function decreases to $0 \mathrm{~g} \mathrm{~mol}^{-1}$. It is expected that smaller counterions (protons) participate during the electrochemical processes between $0.2 \mathrm{~V}$ and $0 \mathrm{~V}^{54}$.

To study the specie composition of "soluble" PB film, a freshly prepared PB film was electrodeposited on ITO electrodes. After the stabilization process in $\mathrm{CsCl}$ aqueous solution, the specie composition of this film was measured through ICP-MS. A Fe/Cs ratio about 0.5 was detected in the stabilized $\mathrm{PB}$ film. However, $\mathrm{Cl}$ was also incorporated into the structure of $\mathrm{PB}$. A Cs/Cl ratio between 1.3 and 1.5 was obtained. Taking into account these results and the postulated formula of "soluble" $\mathrm{PB}$ when $\mathrm{K}^{+}$is the counterion (Eq. [1]), the elemental formula of "soluble" Prussian Blue could be written as:

$$
\mathrm{Fe}_{4}^{\mathrm{III}}\left[\mathrm{Fe}^{\mathrm{II}}(\mathrm{CN})_{6}\right]_{3} \cdot\left[\left(\mathrm{Cs}^{+}\right)_{2} \cdot\left(\mathrm{OH}^{-}\right)_{2} \cdot\left(\mathrm{m}^{\prime} \mathrm{H}_{2} \mathrm{O}\right)\right]_{3} \cdot \mathrm{zCsCl}
$$

The overall entrance of $\mathrm{CsCl}$ implies a strong dehydration that justifies the low electrical conductance observed by mean of EIS respect other alkali cations ${ }^{50}$. Therefore, 
the number of water molecules $\mathrm{m}^{\prime}$ would be lower that its initial value in the freshly deposited PB (around 14-16 molecules per cubic cell) ${ }^{16-18}$.

Meanwhile, $\mathrm{z}$ depends on immersion time of electrodes into the solution of $\mathrm{CsCl}$ taking into account the evolution of mass and $\Delta R_{m}$ in Fig. 1. Along voltammetric cycles, the mass deposited on electrode increases continuously (Fig. 1a). After 10 cycles, the mass deposited on electrode increases about $9 \mu \mathrm{g} \mathrm{cm}{ }^{-2}$. The changes of chemical composition during the stabilization process affect the energy loss of transversal waves from the quartz resonator as it is reflected by the increase of $\Delta R_{m}$ of about $75 \Omega$. To prove this assumption, two "insoluble" $\mathrm{PB}$ films were immersed in $\mathrm{CsCl}$ aqueous solution but only one was stabilized by cyclic voltammetry (Fig. 3).

As Fig. 3a depicts, before the first electrochemical reduction at the beginning of the experiences ( $\mathrm{t}=0$ minutes), a drastic increase of $R_{m}$ of about $300 \Omega$ together with a radical decrease of the resonant frequency of about $5 \mathrm{kHz}$ take place due to the formation of the interfacial region between the "insoluble" PB film and solution. This quick evolution of both magnitudes should be related to the connection of molecules of inner water cluster with aqueous solution. Similar behavior was observed during the formation of the interfacial region when the freshly deposited film without any previous cyclic voltammetry stabilization is immersed into a $\mathrm{CsCl}$ solution (Fig. 3b).

After that, the mass slightly decreases and $\Delta R_{m}$ increases between 0 and 3 minutes in spite of the last minute the conditioning potential $(0.6 \mathrm{~V})$ is applied (Fig. 3a). This evolution is less evident during the potential sweeps, which cause of oscillating mass and $\Delta R_{m}$ changes observed between 3 and 17 minutes (the "apparent" peaks of mass and $\Delta R_{m}$ are the start/final of voltammetric cycles). The slightly evolution of mass and $\Delta R_{m}$ is clearly shown in Fig. 3b where no potential sweep is applied and a continuous decrease of mass and increase of $\Delta R_{m}$ take place. 
These results suggest that in both cases there is a spontaneous entrance of Cs. Therefore, two types of net entrance of Cs are observed. On the one hand, a spontaneous and non-stoichiometric entrance where Cs atoms are located inside the porous of the zeolitic film ${ }^{55}$. In aim to maintain the electrical neutrality, the cesium cation must be accompanied by chloride anion. On the other hand, $\mathrm{Cs}^{+}$is inserted into the $\mathrm{PB}$ film as a counterion in the first electrochemical reduction of the stabilization process by cyclic voltammetry (Fig. 3a at $\mathrm{t}=2.5$ minutes). That is in agreement with $\mathrm{Cs} / \mathrm{Cl}$ ratio obtained by ICP-MS. The excess of 0.3-0.5 ratio from the ideal ratio of $\mathrm{CsCl}(1)$ is due to the $\mathrm{Cs}$ incorporated electrochemically. Simultaneously, part of the water molecules leaves the water cluster. After 50 voltammetric cycles of stabilization or the equivalent time for an immersed "insoluble" $\mathrm{PB}$ film in $\mathrm{CsCl}$ solution (about 75 minutes), the elemental quantities obtained were similar. Fig. 4 shows a schematic representation of PB composition and specie transfer during the reduction process of $\mathrm{PB}$ films in $\mathrm{CsCl}$ acid solution.

From a structural perspective, $R_{m}$ can be considered as a lumped element of BVD circuit with different contributions in the normal direction of modified resonator ${ }^{25-28}$. First, a default contribution due to the manufacturing of electrode resonator $\left(R_{m}^{0}\right)$. Second, a contribution associated with the interface Aulfilm $\left(R_{m}^{A u \mid f i l m}\right)$. Third, a contribution related to the mechanical and magnetic properties of the film $\left(R_{m}^{f i l m}\right)^{28}$. Finally, a fourth superposed contribution associated with the film|solution interfacial region $\left(R_{m}^{\text {film|solution }}\right)$. Theoretically, $R_{m}^{\text {film }}$ would depend on the structure and the inner composition of the film, whilst $R_{m}^{\text {film|solution }}$ would depend on the viscoelasticity of the interfacial region. Presumably, $R_{m}^{0}$ remains constant for each experiment carried out with a particular electrode. Moreover, we can assume that $R_{m}^{A u \mid f i l m}$ depends on the charge transfer but should be of a lower order of magnitude than $R_{m}^{\text {film }}$. Then, a first 
approximation can be written from these assumptions:

$$
\begin{array}{r}
R_{m}=R_{m}^{0}+R_{m}^{\text {Au|film }}+R_{m}^{\text {film }}+R_{m}^{\text {film } \mid \text { solution }} \\
\approx \text { const. }+R_{m}^{\text {film }}+R_{m}^{\text {film } \mid \text { solution }}
\end{array}
$$

where $R_{m}^{\text {film|solution }}$ includes the friction between the film and the solution together with the insertion phenomenon through this interfacial region. This energy loss of the transversal waves between both interfaces is directly related with the viscosity of the solution. Unfortunately, $R_{m}$ includes almost all these previously mentioned contributions.

From a quantitatively point of view, the $R_{m}$ variation can be considered as changes in the elasticity and viscosity in the interfacial region.

$$
\Delta R_{m}=\Delta R_{m}^{\text {film }}+\Delta R_{m}^{\text {film } \mid \text { solution }}
$$

Assuming that the mechanical properties of interfacial region do not change during voltammetric cycles, $R_{m}$ changes are due to changes of composition and viscoelastic properties of PB (the second term of Eq. [5]).

Consequently, $\Delta R_{m}$ evolution in Fig. 1b should depend on density changes or changes of mass because of ionic and non-ionic species exchanges. In this situation, we must be confident that film thickness, the stiffness of rigidity coefficient $\left(G_{f}^{\prime}\right)$ and the loss term $\left(G_{f}^{\prime \prime}\right)$ are constant in the second term of Eq. [5] during the whole stabilization process but this fact is easily feasible for the inorganic crystalline structure of PB films.

Considering both approximations, one can compare qualitatively the results showed in Fig. 1. Whereas vacancies are formed at more cathodic potentials during the reduction reaction of cycle 1 , the more significant variation of mass and $R_{m}$ take place reversibly in the subsequent cycles at potentials more anodic (cycle 10). Accordingly, $R_{m}$ changes after the first reduction reaction of cycle 1 are due exclusively to mass changes, or more specifically, to $\mathrm{Cs}^{+}$exchange as counter ion during the electrochemical reactions. 
In Fig. 5a, time-derivative absorbance at $670 \mathrm{~nm}\left(d A^{670} / d t\right)$ for the first cycle shows the color evolution of the chromophores Fe(II) low spin-CN-Fe(III)high spin which require the alkaline cation participation ${ }^{13}$. This chromophore is the responsible of the blue/white electrochromism of PB. Compared with the voltammetric response, we observe that the electrochemical process stars at a lower cathodic potential range in the voltammogram (early $\mathrm{t}$ in the time scale) than the $d A^{670} / d t$ peak. From a kinetic perspective, the reduction of $\mathrm{Fe}^{\mathrm{III}}$ sites in the walls of crystal vacancies, which involucres the hydrogen ions as counterions (cathodic peak), takes place more easily than the reduction of associated to the spectroscopic band centered at $670 \mathrm{~nm}$ (negative peak of $d A^{670} / d t$ and shoulder around $25 \mathrm{~s}$ ).

The entrance of the $\mathrm{Cs}^{+}$during the first cathodic scan yields the color changes of PB film (negative peak of $d A^{670} / d t$ observed in Fig. 5a). This fact coincides at time (or potential) with the maximum of the $d R_{m} / d t$ function in Fig. 5b, but does not coincides with the $d m / d t$ function (Fig. 6a and b). Consequently, it is necessary the entrance of a certain quantity of $\mathrm{Cs}^{+}$in the PB structure to cause an increase of the rigidity of the film during the first cathodic scan.

Once the PB film is stabilized, the changes modulated of PB elasticity during the potential sweeps takes place around 0.3-0.4 V (Fig. 6a) owing to the exchange of $\mathrm{Cs}^{+}$. Like in the first cycle, $d R_{m} / d t$ (Fig. 6a) and $d m / d t$ (Fig. 6b) peaks are not coincident at the potential scale neither in the reduction process nor in the oxidation process. The most important changes of PB elasticity takes place where PB films accumulate around $75-85 \%$ of Cs inside the structure considering that the mass changes are due mainly to Cs exchange. 


\section{Conclusions}

The simultaneous measurement of current, mass and motional resistance magnitudes allows to explain the changes of elasticity during the electrochemical stabilization of "insoluble" PB film to "soluble" films caused by the exchange cesium. Cesium ions are inserted in the PB structure by means of two process. On the one hand, $\mathrm{CsCl}$ enters spontaneously into the crystalline structure whereas the PB film is immersed in $\mathrm{CsCl}$ acid solution. $\mathrm{CsCl}$ insertion causes the exit of water molecules from the inner water cluster to the solution reducing the electroactivity of PB film. On the other hand, $\mathrm{Cs}^{+}$participates as a counterion in the Prussian Blue (blue) $\leftrightarrows$ Everitt’s salt (uncolored) process. In both process, the insertion of cesium into the PB structure involve an increases of rigidity of the material. For practical uses related to the capture of cesium in aqueous wastes, the electrochemical reduction of "soluble" PB increases the capacity of this polymer to incorporate $\mathrm{Cs}^{+}$inside the crystalline structure.

\section{Acknowledgements}

Part of this work was supported by CICyT project FEDER-CTQ2011-28973/BQU. 


\section{References}

1. K. Itaya, H. Akahoshi, and S. Toshima, J. Electrochem. Soc., 129, 1498-1500 (1982).

2. V. D. Neff, J. Electrochem. Soc., 125, 886-887 (1978).

3. I. Rubinstein, E. Sabatani, and J. Rishpon, J. Electrochem. Soc., 134, 3078-3083 (1987).

4. R. Mortimer, J. Electrochem. Soc., 138, 633-634 (1991).

5. D. Ellis, M. Eckhoff, and V. Neff, J. Phys. Chem., 85, 1225-1231 (1981).

6. K. Itaya, K. Shibayama, H. Akahoshi, and S. Toshima, J. Appl. Phys., 53, 804-805 (1982).

7. K. Itaya, T. Ataka, and S. Toshima, J. Am. Chem. Soc., 104, 4767-4772 (1982).

8. A. Roig, J. Navarro, R. Tamarit, and F. Vicente, J. Electroanal. Chem., 360, 55-69 (1993).

9. R. J. Mortimer and D. R. Rosseinsky, J. Electroanal. Chem., 151, 133-147 (1983).

10. H. Kellawi and D. Rosseinsky, J. Electroanal. Chem., 131, 373-376 (1982).

11. J. Agrisuelas, C. Gabrielli, J. J. Garcia-Jareño, D. Gimenez-Romero, J. Gregori, H. Perrot, and F. Vicente, J. Electrochem. Soc., 154, F134-F140 (2007).

12. P. R. Bueno, F. F. Ferreira, D. Gimenez-Romero, G. O. Setti, R. C. Faria, C. Gabrielli, H. Perrot, J. J. Garcia-Jareno, and F. Vicente, J. Phys. Chem. C, 112, 13264-13271 (2008).

13. J. Agrisuelas, P. R. Bueno, F. F. Ferreira, C. Gabrielli, J. J. Garcia-Jareño, D. Gimenez-Romero, H. Perrot, and F. Vicente, J. Electrochem. Soc., 156, P74-P80 (2009).

14. D. R. Rosseinsky and A. Glidle, J. Electrochem. Soc., 150, C641-C645 (2003).

15. B. Bal, S. Ganguli, and M. Bhattacharya, J. Phys. Chem., 88, 4575-4577 (1984).

16. S. Ganguli and M. Bhattacharya, J. Chem. Soc.-Faraday Trans. I, 79, 1513-1522 (1983).

17. D. Giménez-Romero, P. R. Bueno, J. J. García-Jareño, C. Gabrielli, H. Perrot, and F. Vicente, J. Phys. Chem. B, 110, 2715-2722 (2006).

18. H. Buser, D. Schwarzenbach, W. Petter, and A. Ludi, Inorg. Chem., 16, 2704-2710 (1977).

19. J. Agrisuelas, J. Juan Garcia-Jareño, D. Gimenez-Romero, and F. Vicente, J. Electrochem. Soc., 156, P149-P156 (2009).

20. K. A. Marx, Biomacromolecules, 4, 1099-1120 (2003). 
21. G. Sauerbrey, Z. Für Phys., 155, 206-222 (1959).

22. R. A. Etchenique and E. J. Calvo, Electrochem. Commun., 1, 167-170 (1999).

23. R. A. Etchenique and E. J. Calvo, Anal. Chem., 69, 4833-4841 (1997).

24. M. A. Mohamoud and A. R. Hillman, Electrochimica Acta, 53, 1206-1216 (2007).

25. H. Muramatsu, E. Tamiya, and I. Karube, Anal. Chem., 60, 2142-2146 (1988).

26. S. Martin, V. Granstaff, and G. Frye, Anal. Chem., 63, 2272-2281 (1991).

27. V. Granstaff and S. Martin, J. Appl. Phys., 75, 1319-1329 (1994).

28. D. Gimenez-Romero, J. Agrisuelas, J. J. Garcia-Jareño, J. Gregori, C. Gabrielli, H. Perrot, and F. Vicente, J. Am. Chem. Soc., 129, 7121-7126 (2007).

29. M. A. Cooper and V. T. Singleton, J. Mol. Recognit., 20, 154-184 (2007).

30. P. Taranekar, T. Fulghum, D. Patton, R. Ponnapati, G. Clyde, and R. Advincula, J. Am. Chem. Soc., 129, 12537-12548 (2007).

31. C. Gabrielli, A. A. O. Magalhaes, I. C. P. Margarit, H. Perrot, and B. Tribollet, Electrochem. Commun., 6, 492-498 (2004).

32. F. Xie, Z. Huang, C. Chen, Q. Xie, Y. Huang, C. Qin, Y. Liu, Z. Su, and S. Yao, Electrochem. Commun., 18, 108-111 (2012).

33. D. Buttry and M. Ward, Chem. Rev., 92, 1355-1379 (1992).

34. I. Jureviciute, S. Bruckenstein, A. R. Hillman, and A. Jackson, Phys. Chem. Chem. Phys., 2, 4193-4198 (2000).

35. R. Borjas and D. Buttry, J. Electroanal. Chem., 280, 73-90 (1990).

36. J. J. Garcia-Jareño, C. Gabrielli, and H. Perrot, Electrochem. Commun., 2, 195-200 (2000).

37. K. Kaneto and M. Kaneko, Appl. Biochem. Biotechnol., 96, 13-23 (2001).

38. L. Lizarraga, E. M. Andrade, M. I. Florit, and F. V. Molina, J. Phys. Chem. B, 109, 18815-18821 (2005).

39. L. T. T. Kim, C. Gabrielli, A. Pailleret, and H. Perrot, Electrochimica Acta, 56, 35163525 (2011).

40. Y. Lee, C. Chang, S. Yau, L. Fan, Y. Yang, L. O. Yang, and K. Itaya, J. Am. Chem. Soc., 131, 6468-6474 (2009).

41. A. Fernandez-Barbero, I. J. Suarez, B. Sierra-Martin, A. Fernandez-Nieves, F. Javier de las Nieves, M. Marquez, J. Rubio-Retama, and E. Lopez-Cabarcos, Adv. Colloid Interface Sci., 147-48, 88-108 (2009). 
42. A. R. Hillman, M. A. Mohamoud, and I. Efimov, Anal. Chem., 83, 5696-5707 (2011).

43. J. Agrisuelas, J. J. Garcia-Jareño, D. Gimenez-Romero, and F. Vicente, Electrochimica Acta, 54, 6046-6052 (2009).

44. P. Haas, Sep. Sci. Technol., 28, 2479-2506 (1993).

45. C. Thammawong, P. Opaprakasit, P. Tangboriboonrat, and P. Sreearunothai, J. Nanoparticle Res., 15 (2013).

46. P. J. Faustino, Y. Yang, J. J. Progar, C. R. Brownell, N. Sadrieh, J. C. May, E. Leutzinger, D. A. Place, E. P. Duffy, F. Houn, S. A. Loewke, V. J. Mecozzi, C. D. Ellison, M. A. Khan, A. S. Hussain, and R. C. Lyon, J. Pharm. Biomed. Anal., 47, 114-125 (2008).

47. K. Kosaka, M. Asami, N. Kobashigawa, K. Ohkubo, H. Teracia, N. Kishicla, and M. Akiba, Water Res., 46, 4397-4404 (2012).

48. I. Oh, H. Lee, H. Yang, and J. Kwak, Electrochem. Commun., 3, 274-280 (2001).

49. J. Agrisuelas, C. Delgado, C. Gabrielli, J. J. Garcia-Jareño, H. Perrot, and F. Vicente, ECS Trans., 35, 53-61 (2011).

50. J. J. Garcia-Jareño, J. Navarro-Laboulais, A. Sanmatias, and F. Vicente, Electrochimica Acta, 43, 1045-1052 (1998).

51. J. J. Garcia-Jareño, A. Sanmatias, D. Benito, J. Navarro-Laboulais, and F. Vicente, Int. J. Inorg. Mater., 1, 343-349 (1999).

52. J. J. García-Jareño, D. Giménez-Romero, F. Vicente, C. Gabrielli, M. Keddam, and H. Perrot, J. Phys. Chem. B, 107, 11321-11330 (2003).

53. J. Garcia-Jareño, A. Sanmatias, J. Navarro-Laboulais, and F. Vicente, Electrochimica Acta, 44, 395-405 (1998).

54. J. J. Garcia-Jareño, J. Navarro-Laboulais, and F. Vicente, Electrochimica Acta, 41, 835-841 (1996).

55. H. Fujita, R. Miyajima, and A. Sakoda, Adsorption, 21, 195-204 (2015). 


\section{Figure captions}

Fig. 1. Mass variation (a) and motional resistance (b) of the first cycle and $10^{\text {th }}$ cycle during the stabilization process in $0.5 \mathrm{M} \mathrm{CsCl}(\mathrm{pH} 2.7)$ of a $\mathrm{PB}$ film deposited on $\mathrm{Au}$ electrode $\left(S=20.02 \mathrm{~mm}^{2}\right)$. The reference electrode is $\mathrm{Ag}|\mathrm{AgCl}| \mathrm{KCl}_{(\mathrm{sat})} ; v=20 \mathrm{mV} \mathrm{s}^{-1}$; $T=299 \mathrm{~K}$. The resonance of quartz crystal is $9 \mathrm{MHz}$.

Fig. 2. $F(d m / d q)$ variation and current response of the first cycle (a) and $10^{\text {th }}$ cycle (b) during the stabilization process in $0.5 \mathrm{M} \mathrm{CsCl}(\mathrm{pH}$ 2.7) of a $\mathrm{PB}$ film deposited on $\mathrm{Au}$ electrode $\left(S=20.02 \mathrm{~mm}^{2}\right)$. The reference electrode is $\mathrm{Ag}|\mathrm{AgCl}| \mathrm{KCl}_{\text {(sat) }} ; v=20 \mathrm{mV} \mathrm{s}^{-1}$; $T=299 \mathrm{~K}$. Closed circles indicate the cathodic direction and open circles are the anodic direction of the potential sweep. The resonance of quartz crystal is $9 \mathrm{MHz}$ and $F$ is the Faraday number.

Fig. 3. Evolution of resonant frequency $f$ and motional resistance $R_{m}$ vs time during the voltammetric stabilization experiment (a) and by immersion in solution (b) of a PB film deposited on Au electrode $\left(S=20.02 \mathrm{~mm}^{2}\right)$ in $0.5 \mathrm{M} \mathrm{CsCl}(\mathrm{pH}=2.7)$. The resonance of quartz crystal is $9 \mathrm{MHz}$.

Fig. 4. Schematic approximation of $P B$ structure and ionic channels where the participating species can be inserted during the stabilization process. Arrows indicate specie transfer during a reduction process.

Fig. 5. $d A^{670} / d t$ variation (a) and $d R_{m} / d t$ variation (b) vs time with the current response of the first cycle of the stabilization process in $0.5 \mathrm{M} \mathrm{CsCl}(\mathrm{pH} 2.7)$ of a $\mathrm{PB}$ film deposited on Au electrode $\left(S=20.02 \mathrm{~mm}^{2}\right)$. The reference electrode is $\mathrm{Ag}|\mathrm{AgCl}| \mathrm{KCl}$ (sat); $v=20$ $\mathrm{mV} \mathrm{s}^{-1} ; T=299 \mathrm{~K}$. The resonance of quartz crystal is $9 \mathrm{MHz}$. 
Fig. 6. $d R_{m} / d t$ variation (a) $d m / d t$ variation (b) of the first cycle and 10th cycle during the stabilization process in $0.5 \mathrm{M} \mathrm{CsCl}(\mathrm{pH} 2.7)$ of a $\mathrm{PB}$ film deposited on Au electrode $\left(S=20.02 \mathrm{~mm}^{2}\right)$. The reference electrode is $\mathrm{Ag}|\mathrm{AgCl}| \mathrm{KCl}_{\text {(sat) }} ; v=20 \mathrm{mV} \mathrm{s}^{-1} ; T=299 \mathrm{~K}$. The resonance of quartz crystal is $9 \mathrm{MHz}$. 
8. Figures

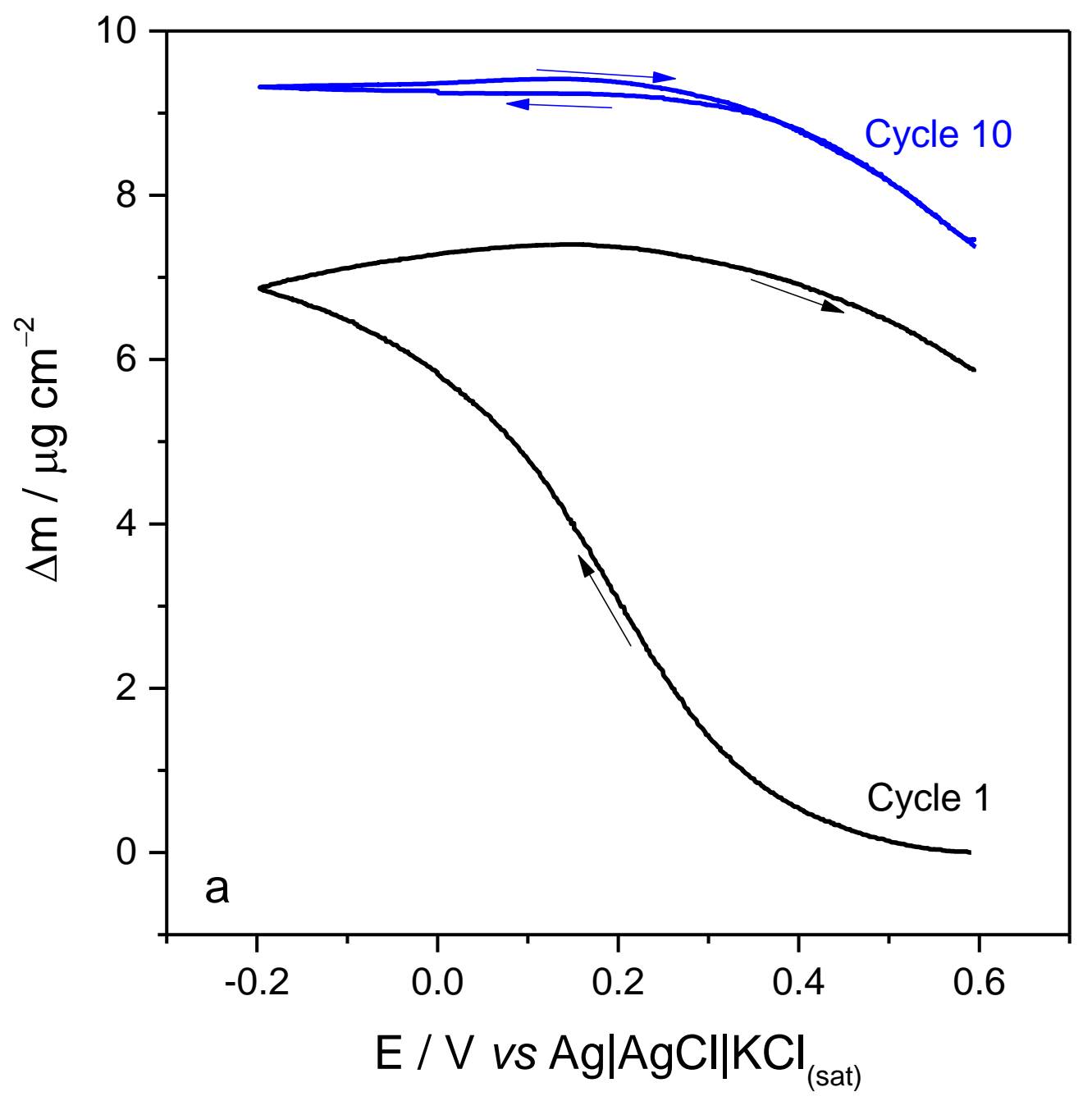

Fig. 1a 


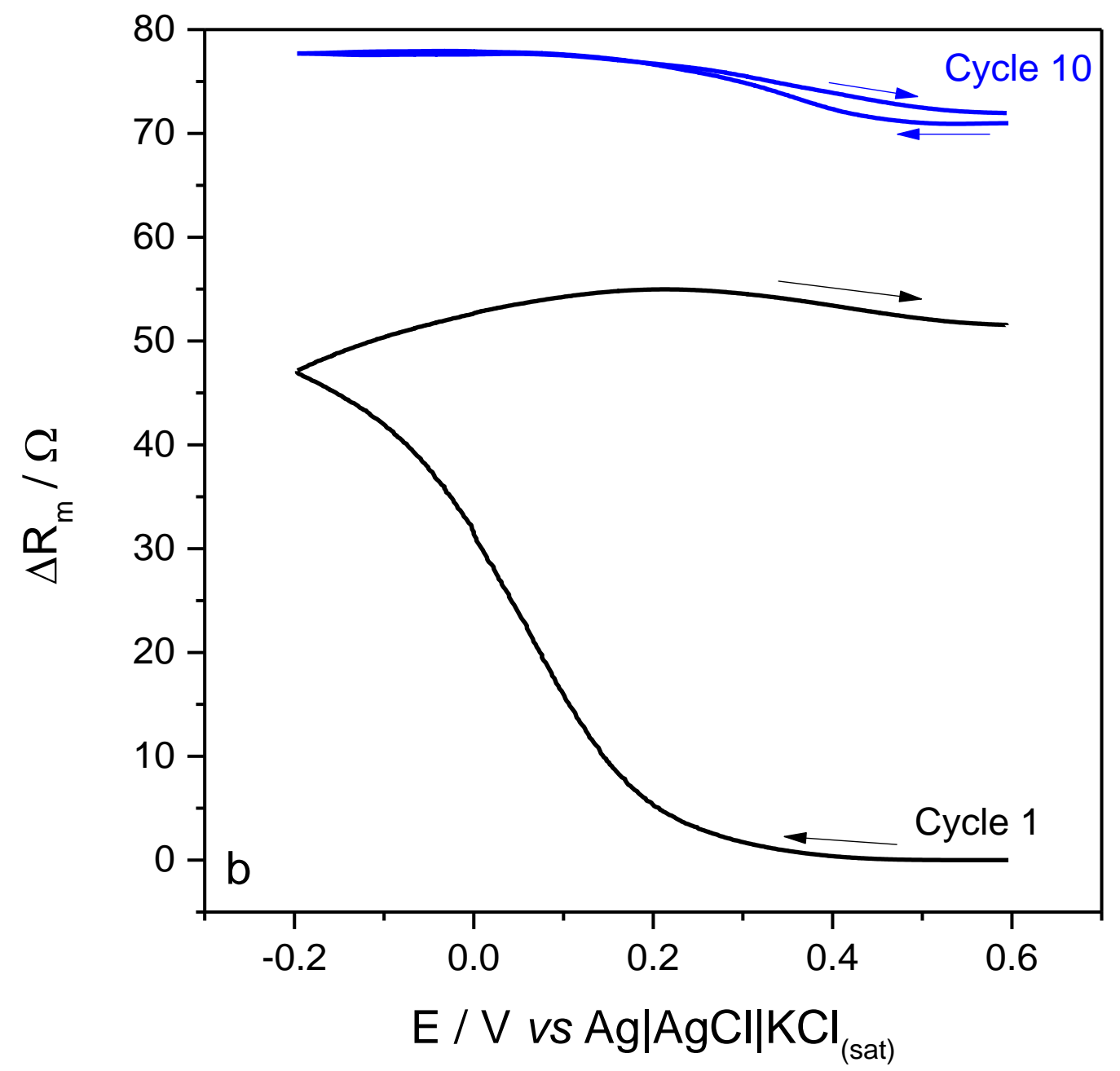

Fig. 1b 


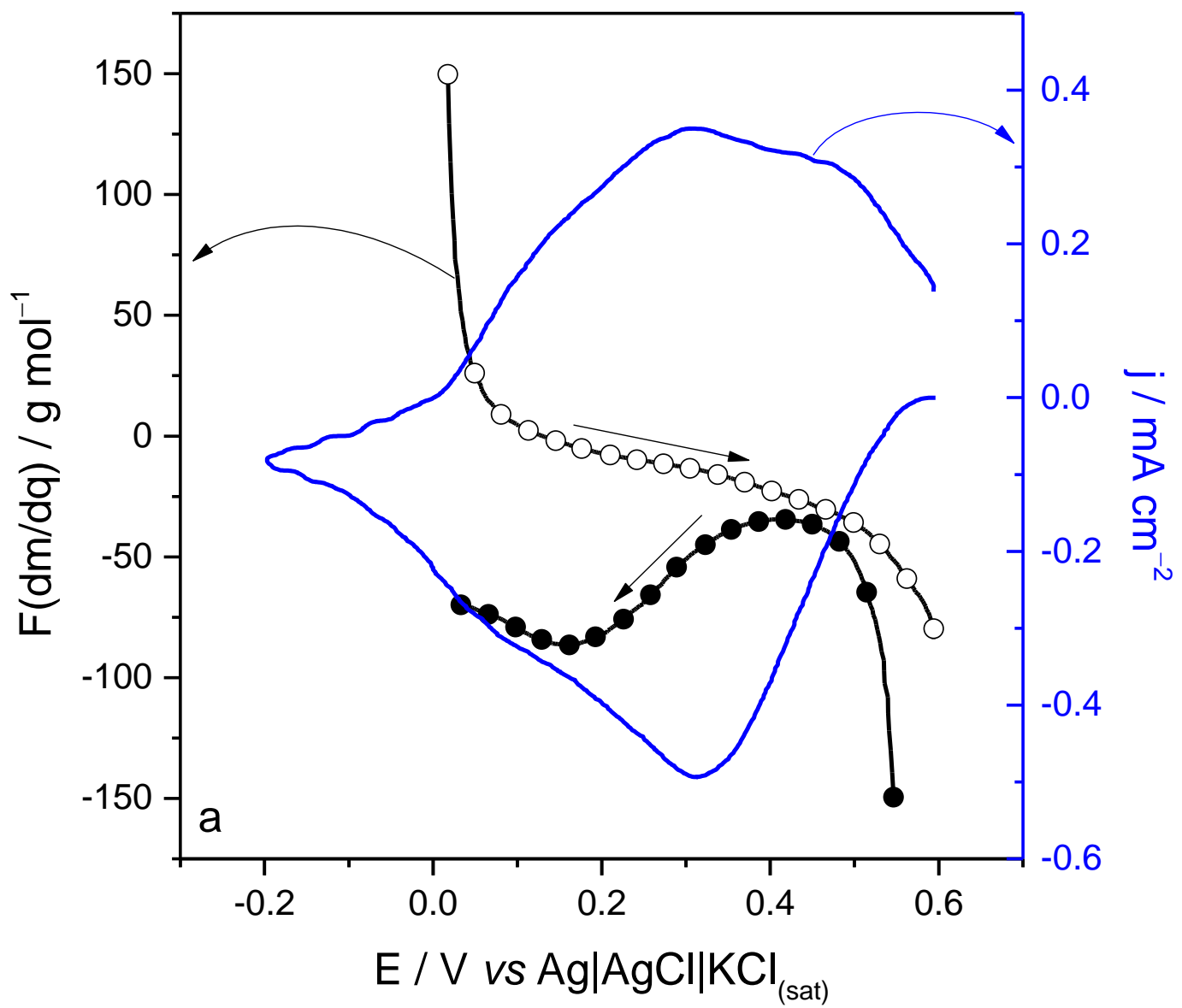

Fig. 2a 


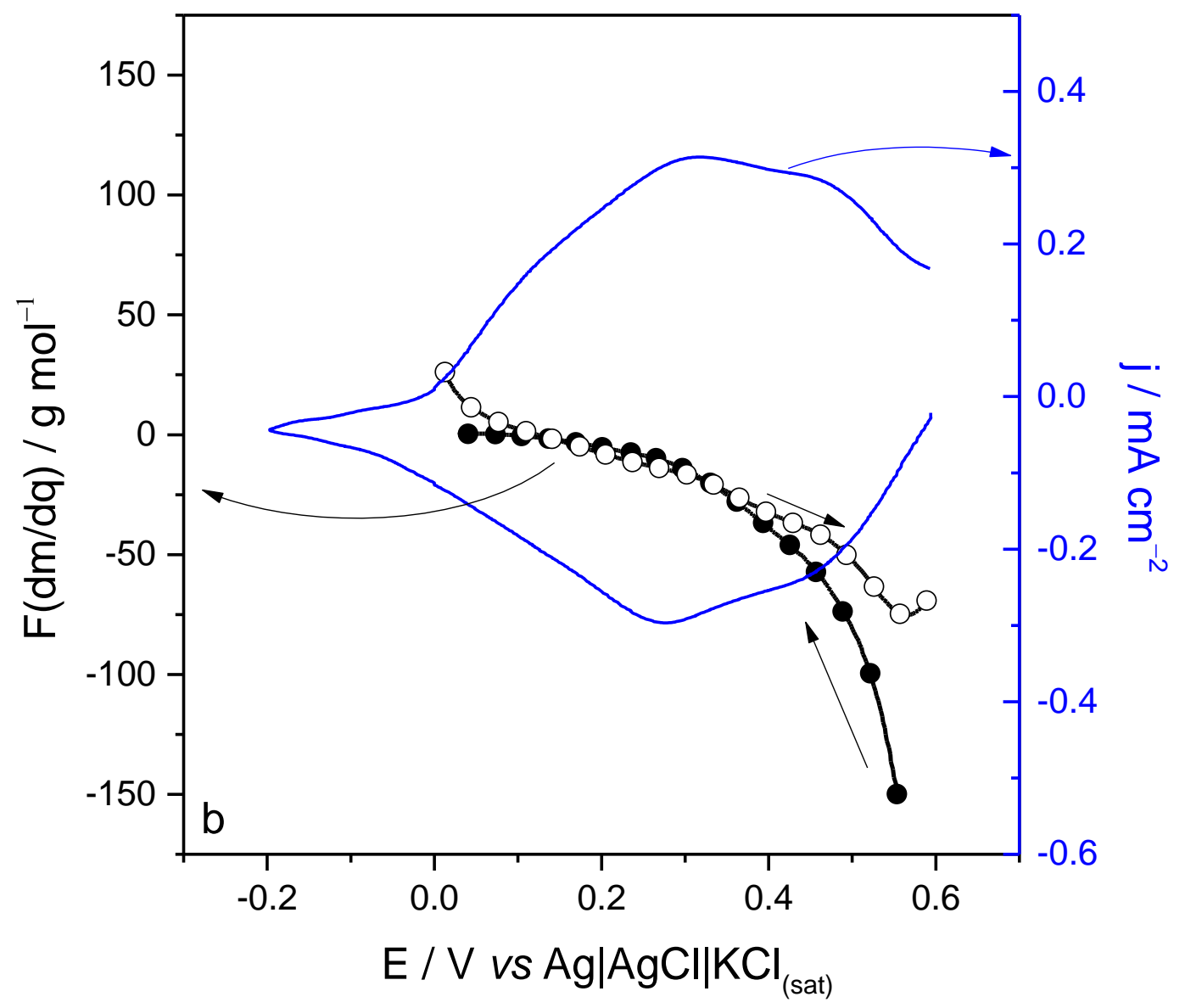

Fig. 2b 


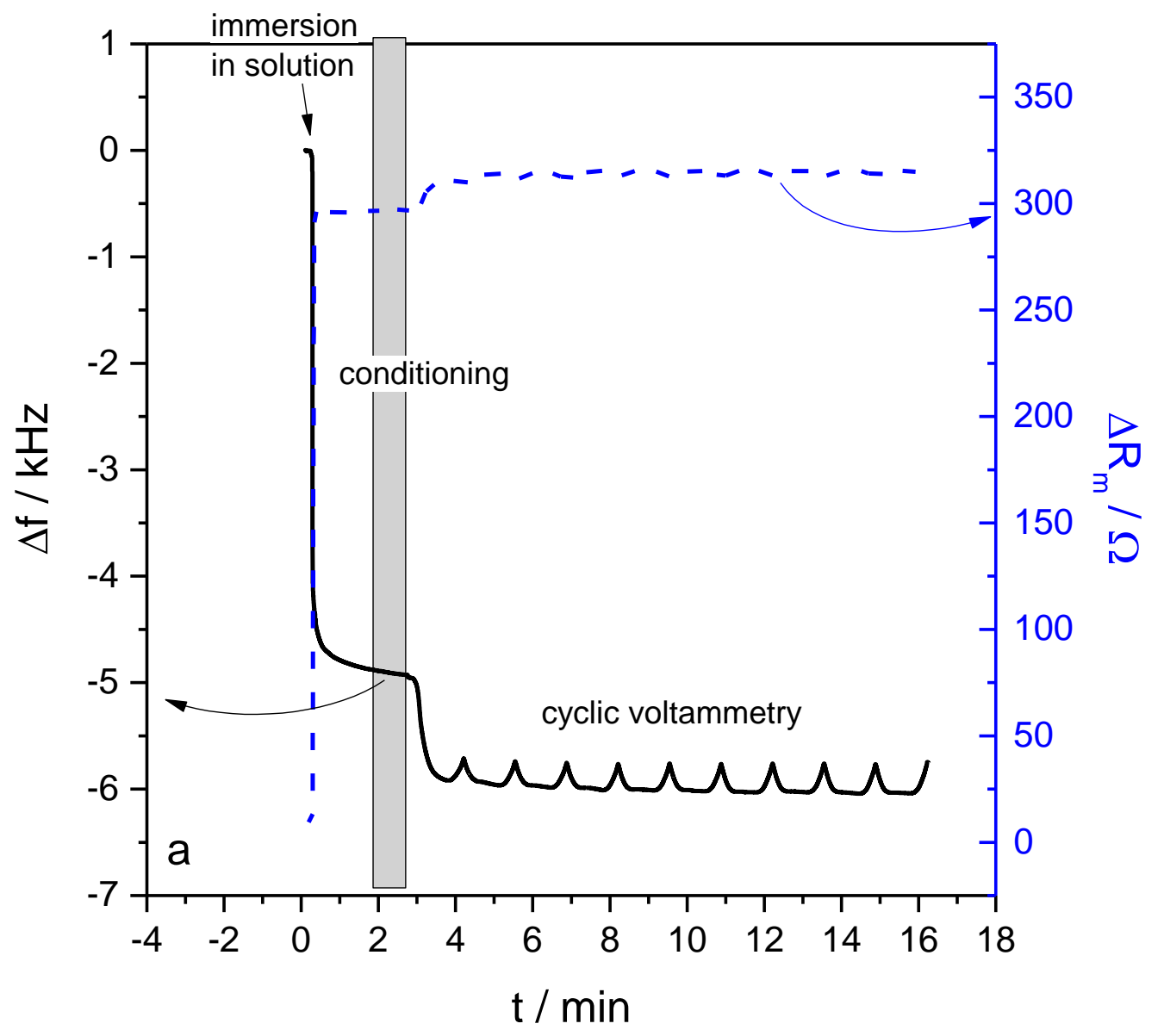

Fig. 3a 


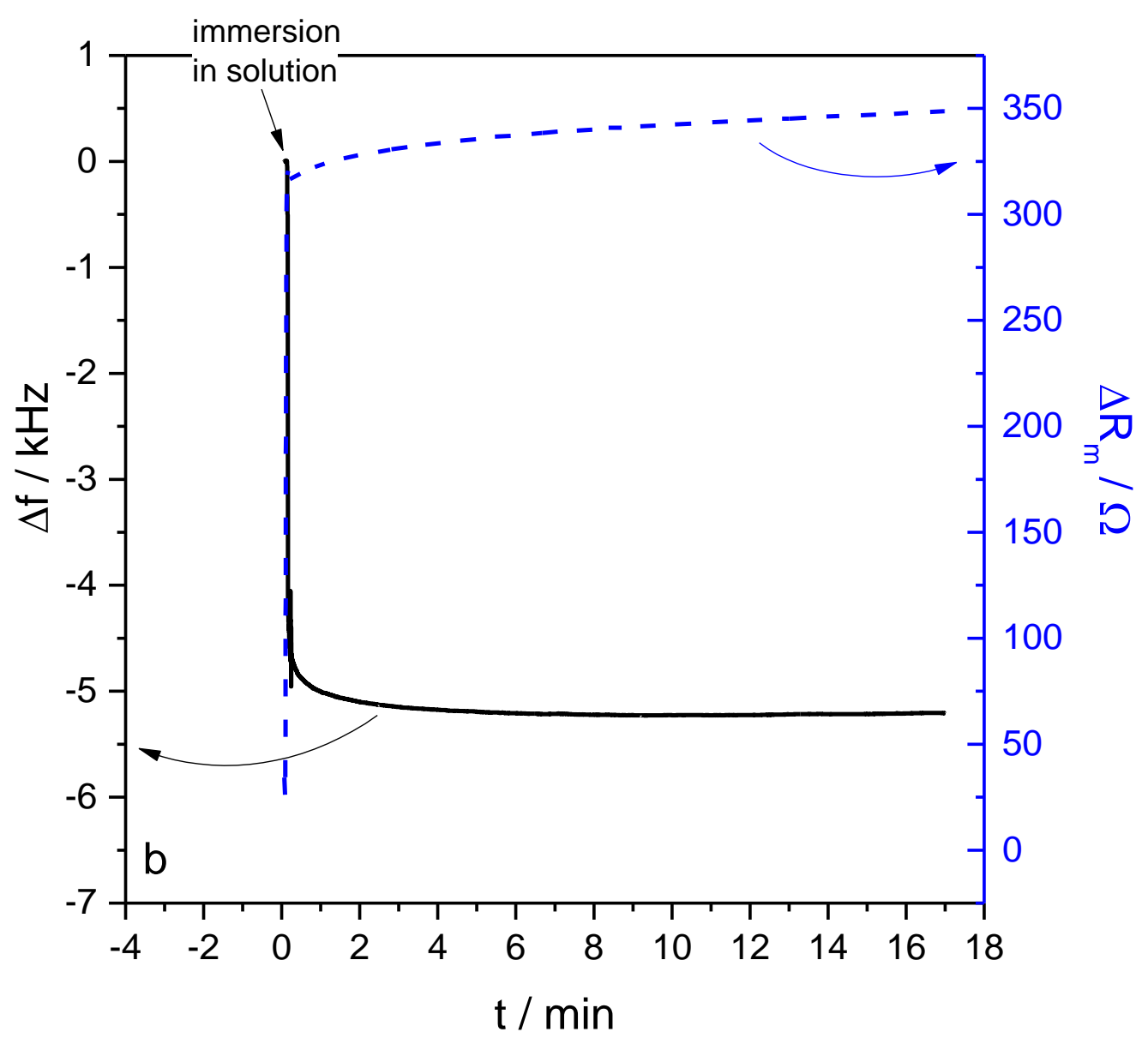

Fig. 3b 

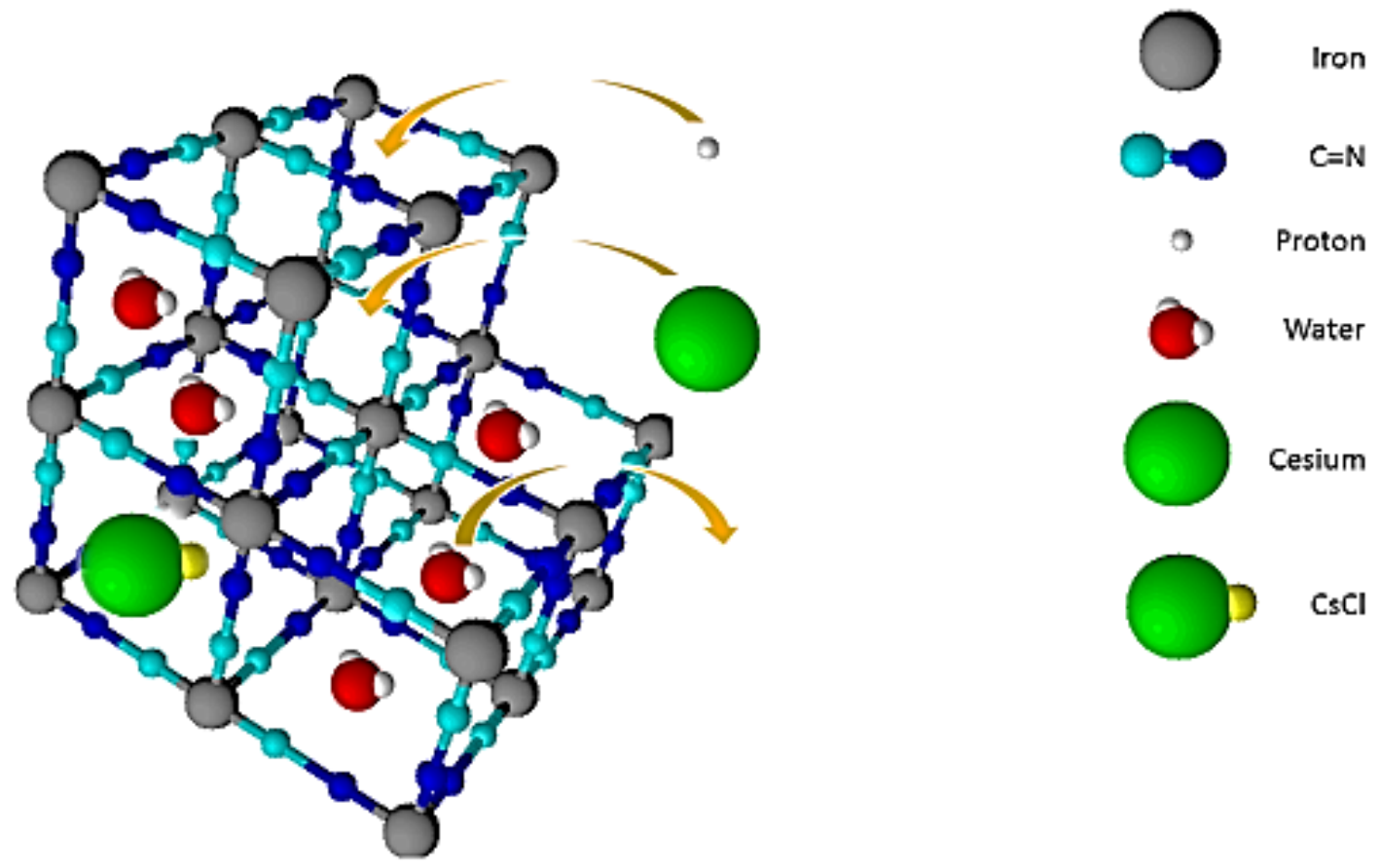

Fig. 4 


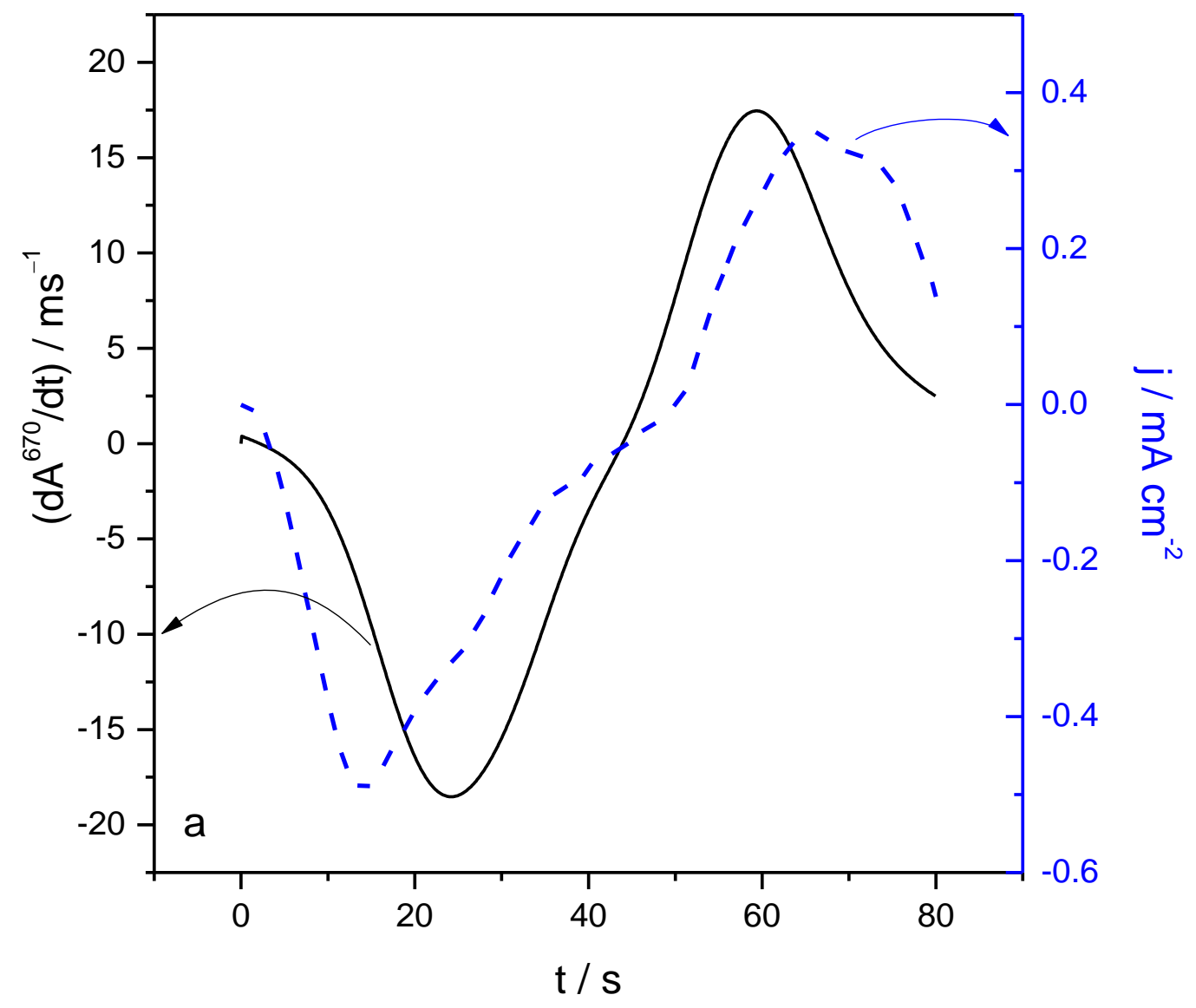

Fig. 5a 


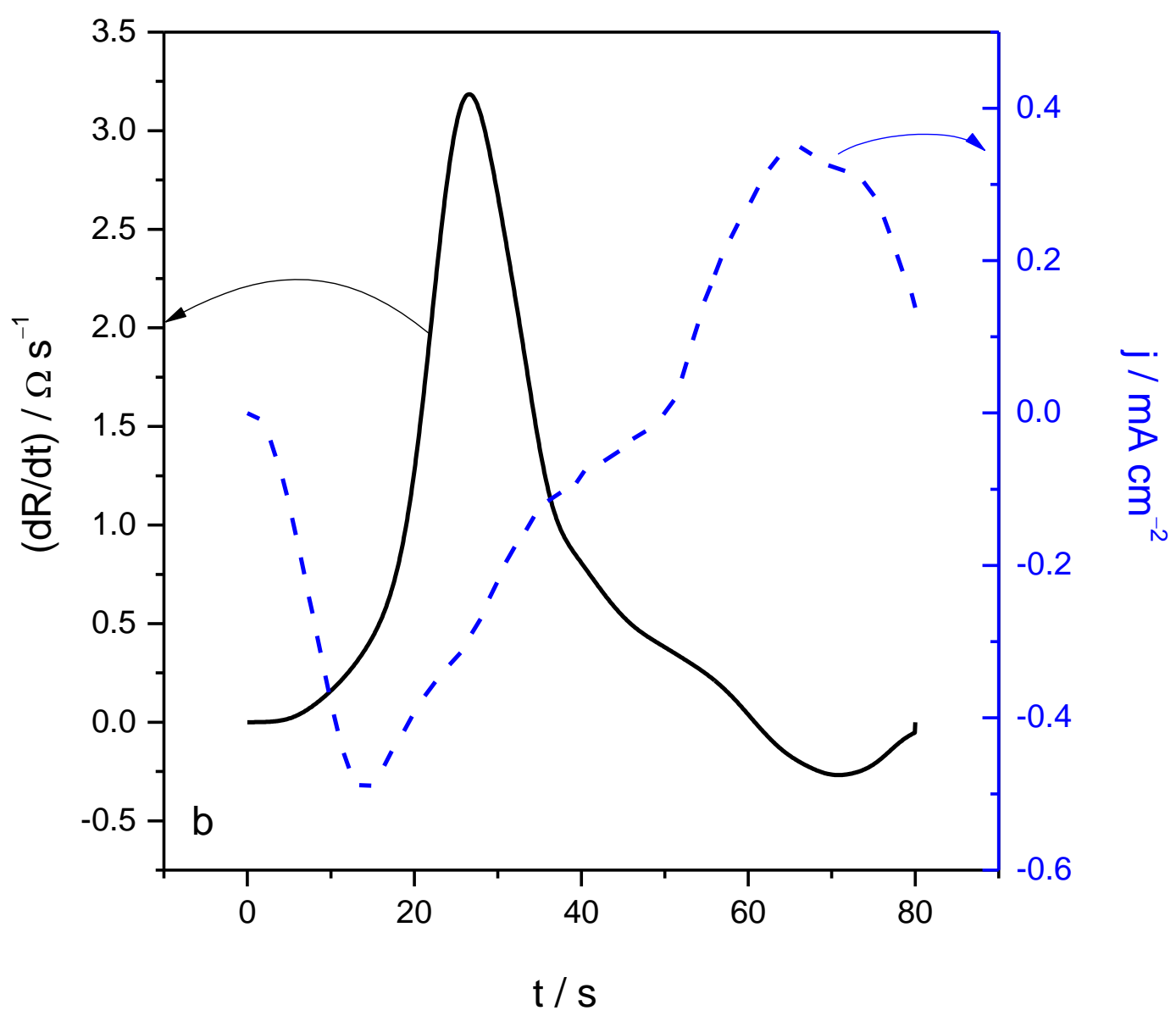

Fig. 5b 


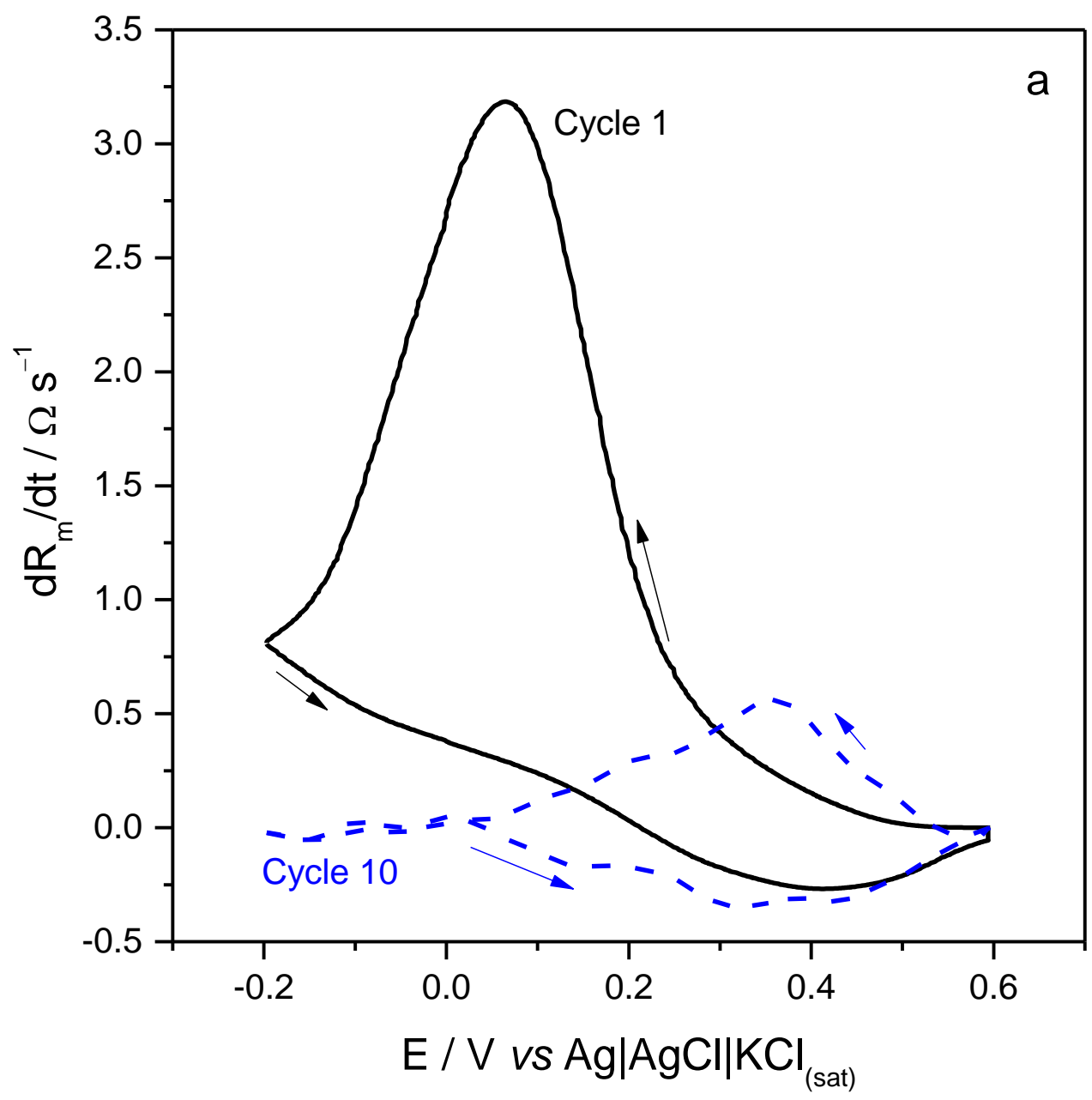

Fig. 6a 


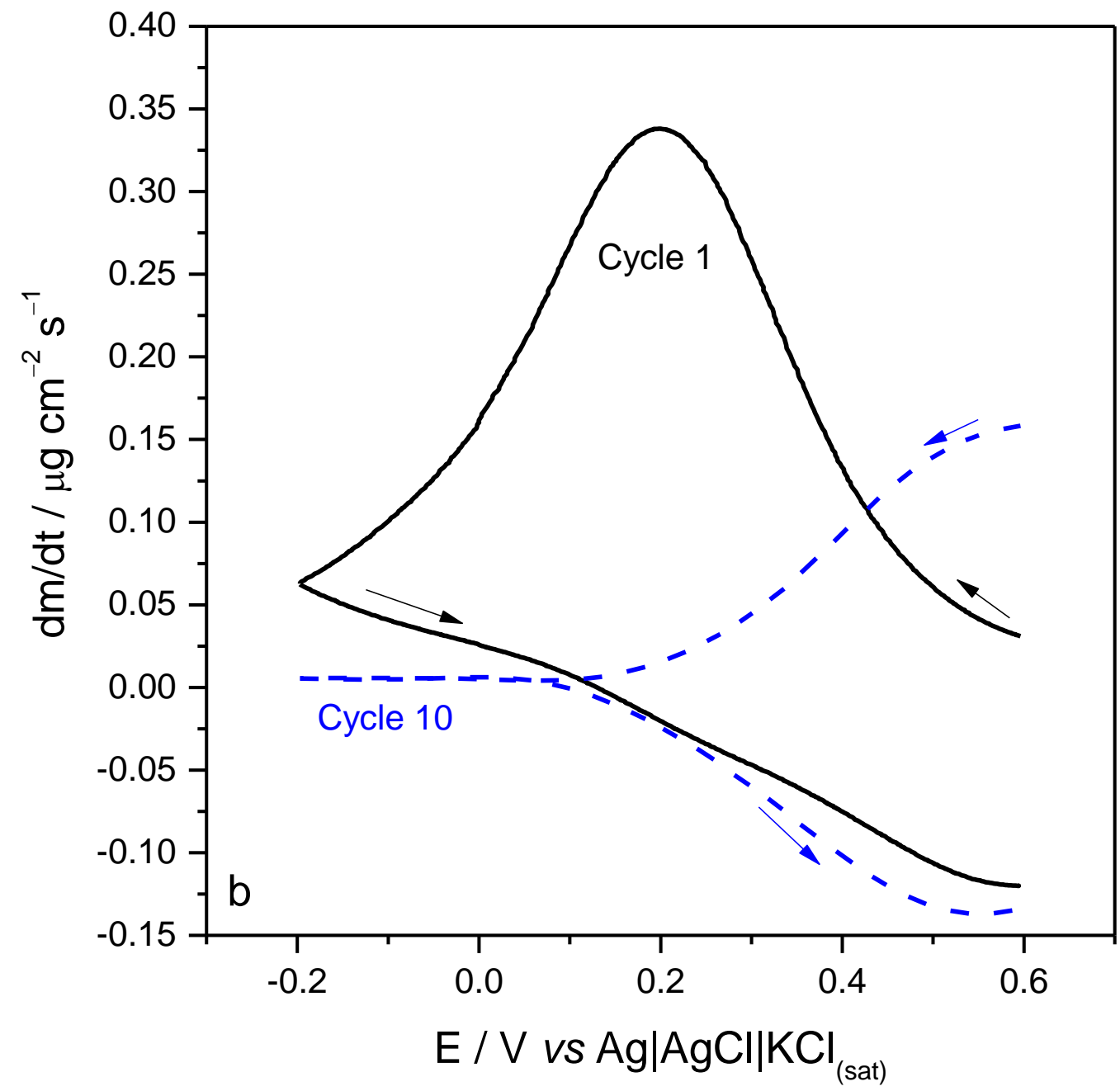

Fig. 6b 